\title{
CT-Guided Percutaneous Core Needle Biopsy for Lung Lesions: A 14-Year Review of Needle Angle and Lesion Depth
}

\author{
Jee Hyeon Lee (iD) ${ }^{1}$ and In Jae Lee (iD $)^{2, *}$ \\ ${ }^{1}$ Department of Radiology, Hallym University Sacred Heart Hospital, Gyeonggi-do, Republic of Korea \\ ${ }^{2}$ Department of Radiology, Hallym University College of Medicine, Anyang, Republic of Korea \\ "Corresponding author: Department of Radiology, Hallym University Sacred Heart Hospital, Gwanpyeong-ro 170 Beon-gil, Dongan-gu, Angang, Gyeonggi-do, Republic of Korea. \\ Tel: +82-313803878, Email: ijlee2003@naver.com
}

Received 2019 July 10; Revised 2020 March 17; Accepted 2020 March 21.

\begin{abstract}
Background: Increasing success rate and reducing complications are important for computed tomography (CT)-guided percutaneous core needle biopsy (PCNB).

Objectives: To assess the influence of needle angle and lesion depth on procedural success and complications of CT-guided PCNB for intrapulmonary lesions, performed by a single radiologist.

Patients and Methods: A total of 689 cases of PCNB performed under CT guidance were enrolled in this study. The collected data were retrospectively reviewed. The pathologic results and complications were evaluated for each case. Two factors-needle angle and lesion depth-were statistically analyzed to assess the relationship with procedural success and complications of PCNB by using univariate analysis. Post hoc analysis was performed with Bonferroni's method.

Results: The overall success rate was 93.1\% (642/689). Procedural success showed no statistically significant association with both needle angle $(\mathrm{P}=0.568)$ and lesion depth $(\mathrm{P}=0.144)$. The overall complication rate was $17.9 \%(123 / 689)$ with $15.7 \%$ for minor complications and $2.2 \%$ for major complications. The needle angle had no association with complications $(\mathrm{P}=0.101)$. Presence and severity of complications showed a direct relationship with lesion depth $(\mathrm{P}<0.01)$. In fact, more severe complications occurred in deeper located lesions.

Conclusion: Needle angle had no effect on both procedural success and complications. Also, there was no significant correlation between lesion depth and procedural success. However, lesion depth was closely correlated with the incidence and severity of complications after PCNB.
\end{abstract}

Keywords: Biopsy, lung, complications, CT

\section{Background}

Computed tomography (CT)-guided percutaneous core needle biopsy (PCNB) is a well-established method and regarded as a relatively safe procedure for the diagnosis of intrapulmonary lesions (1). The main purpose of this technique is to obtain a large volume of tissue, sufficient for pathologic confirmation with minimal complications. Therefore, it is important to identify factors that might affect the outcome of the procedure. There have been a few reports suggesting various factors affecting complications and success rates of PCNB, including lesion size, number of needle insertion, lesion depth and underlying lung disease such as emphysema (2-6). Among numerous analyzed factors, needle angle showed inconsistent and conflicting results in previous literatures $(2,5,6)$. However, in the actual clinical practice of our institute, the larger the angle, the more complications seemed to occur.
In contrast to needle angle, lesion depth is a relatively well-known factor influencing the outcome of the procedure. However, most published reports have analyzed procedures performed by several radiologists with various levels of experience, which can influence the complications and success rates of $\operatorname{PCNB}(3,4)$. To our knowledge, of the numerous studies conducted so far, no major reports have evaluated procedures excluding the influence of the radiologist. Moreover, most prior studies were limited by a small population size $(3,4)$.

\section{Objectives}

This study aimed to assess the influence of two factorsneedle angle and lesion depth-on the procedural success and complications of CT-guided PCNBs using a core needle, through retrospective review of a relatively large number 
of cases $(n=689)$, in which all procedures were performed by a single radiologist.

\section{Patients and Methods}

\subsection{Patients}

From July 2004 to March 2017, CT-guided PCNBs were performed for intrapulmonary lesions in 834 cases. Among the 834 eligible cases, the exclusion criteria were as follows: (1) cases with more than one needle pass during a single biopsy attempt; and (2) cases with unmatched biopsy result. We excluded 141 cases $(n=141)$ with additional passes, as these passes might impact complication rate. However, repeated biopsies with an at-least a 1-day interval between attempts ( 54 cases in 27 patients) were included in the study because we assumed that at least a 1-day interval would not affect the incidence of complications. Only one specimen was obtained per one biopsy attempt. In four cases $(n=4)$, the histopathologic result of PCNB (which was originally categorized as procedural success) differed from that of surgical or bronchoscopic biopsy performed at the same site. These ambiguous four cases were also excluded from the study. Finally, 689 results from 662 patients underwent statistical analysis (Figure 1).

We use a core needle lung biopsy and all cases were performed with an automated biopsy gun using an 18-gauge needle (Magnum ${ }^{\circledR}$, Bard) regardless of the character of the patient and lesion. Stroke length was chosen between 1.5 $\mathrm{cm}$ and $2.2 \mathrm{~cm}$ depending on lesion size. All procedures were performed using CT (Hispeed, GE Medical Systems, Milwaukee, WI, USA or Sensation 64, Siemens Healthcare, Forchheim, Germany). Patient's posture was changed to prone, supine, or oblique position, depending on the location of the lesion. The puncture site of the pleura and the needle pathway were chosen in a manner that ensured the shortest possible distance from the lesion to the pleura, based on CT scan data. All PCNBs were performed by one skilled chest radiologist. All cases were retrospectively reviewed with the approval of the institutional review board.

\subsection{Data Analysis}

The needle angle and lesion depth were calculated for each case. A virtual line perpendicular to the CT table (line A), and another line parallel to the needle pathway (line B), were created. The angle was determined by measuring the acute angle between line $\mathrm{A}$ and line $\mathrm{B}$ (Figure 2 ). The angle was subdivided into three categories: $0^{\circ}-30^{\circ}, 31^{\circ}-60^{\circ}$, and $61^{\circ}-90^{\circ}$. The depth from the pleural surface was measured from the point of pleural puncture to the nearest edge of the lung lesion along the needle pathway (Figure 3). The depth was recorded as a continuous variable.
Pathologic results and complications were evaluated to assess their relationship with the needle angle and the lesion depth from the pleural surface. Procedural success was defined as completion of the biopsy procedure with diagnostic results; procedural failure was defined as an inconclusive histopathologic result due to inadequate tissue or nonspecific findings. In case of nonspecific findings (e.g., chronic inflammation), follow-up for at least 18 months was performed. During follow up period, a final categorization of procedural success was made if (1) the lesion remained stable or decreased in size; or (2) a specific benign diagnosis was confirmed by surgical pathology. Complications were categorized as minor or major, based on cardiovascular and interventional radiological society of Europe (CIRSE) classification system for complications. The CIRSE guideline is a standardized grading system of complications based on combining outcome, therapy, and severity of sequelae (7). According to this classification, if it belonged to grade 1 or grade 2 , it was classified as a minor complication. Complications that continued for more than 48 hours or needed additional procedures were categorized as major complications. This group belongs to grade 3 or higher according to CIRSE classification system. Complications were evaluated by using the CT scan obtained immediately after PCNB, follow-up chest radiographs 2 hours after PCNB, and chest radiographs taken after the next morning, as well as by reviewing electronic medical records. Each patient's age, sex, and lesion size and location were also recorded. Coagulation disorder was not recorded because the procedure was performed after correction of coagulation factors. Presence of emphysema was not recorded either.

To investigate if there were differences by the number of years of experience of a radiologist, the study period, 153 months, was divided into three groups of 51 months each to compare the rate of complications and procedural success: group 1, from July 2004 to September 2008; group 2, from October 2008 to December 2012; group 3, from January 2013 to March 2017.

\subsection{Statistical Analysis}

Statistical analysis was performed using the SPSS 26.0 statistical software package (IBM SPSS, Armonk, NY, USA). Univariate statistical analysis was performed using a trend test for a categorized variable (needle angle). The lesion depth, belonging to continuous variable, was analyzed by using the Kruskal-Wallis test and the Mann-Whitney U test when comparing relationship with complications and procedural success, respectively. Differences at $\mathrm{P}<0.05$ were considered to be statistically significant. On post hoc analysis for multiple comparisons, the Pvalue was corrected using Bonferroni's method. A P value less than 0.0167 (0.05/3) 


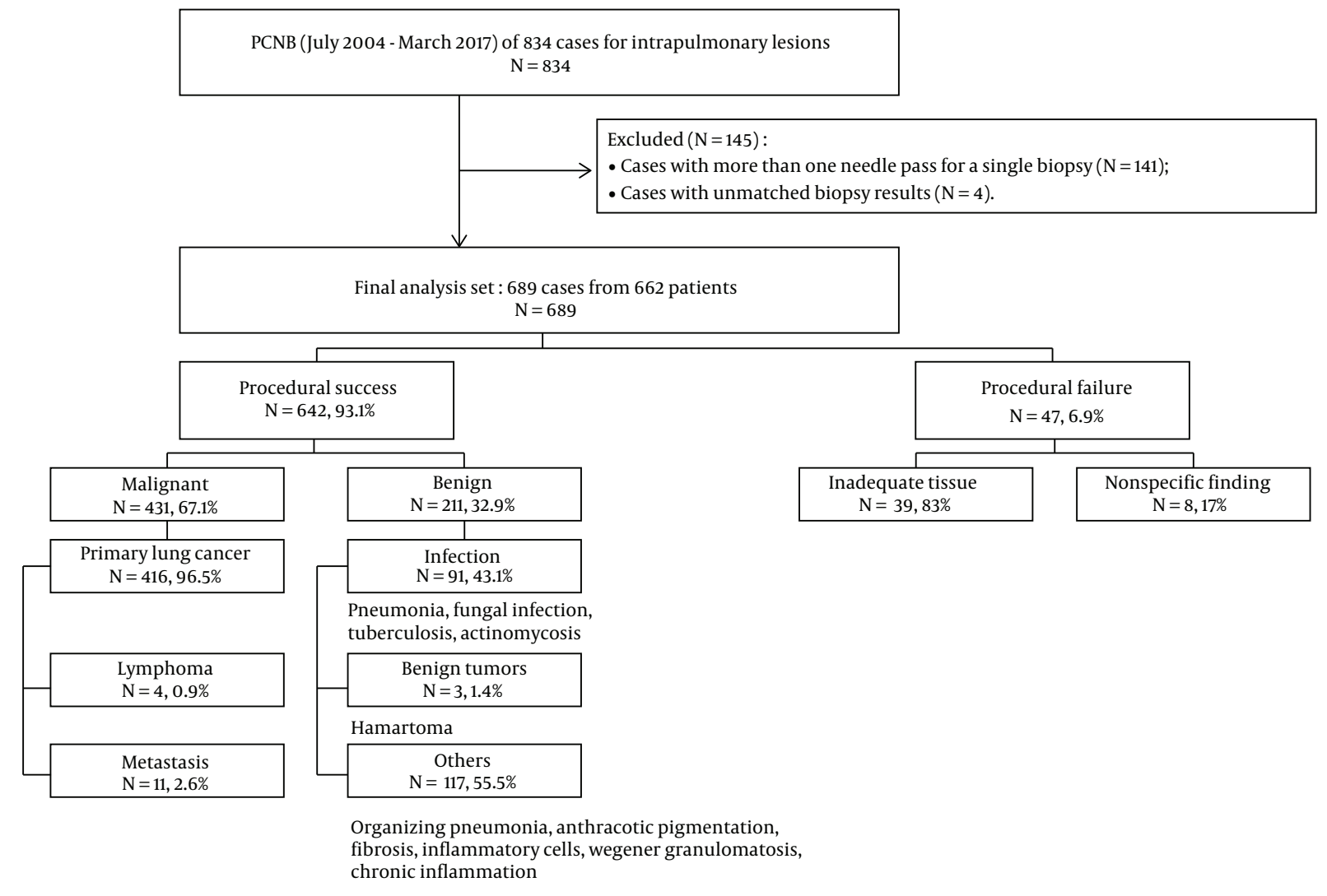

Figure 1. Flow chart shows patient selection and exclusion criteria with the distribution of biopsy results.

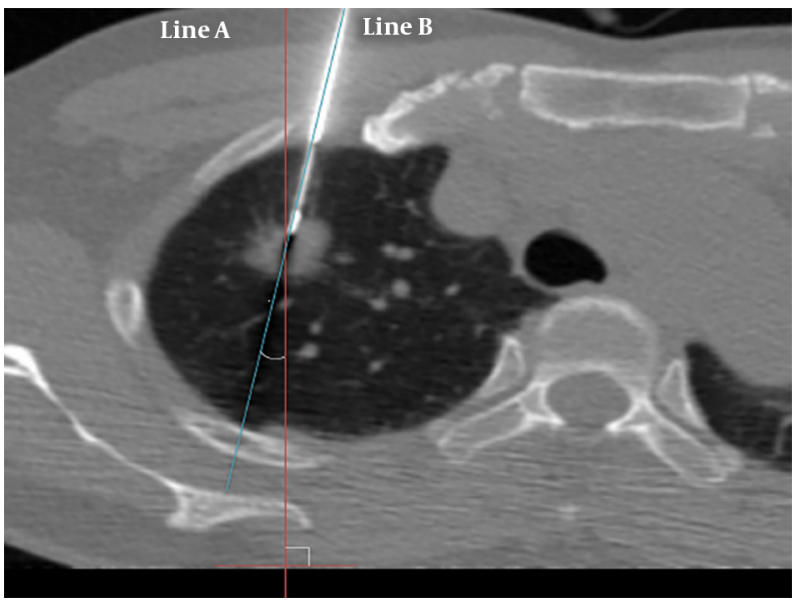

Figure 2. Line $\mathrm{A}$ is virtual line perpendicular to the $\mathrm{CT}$ table; line $\mathrm{B}$ is drawn paralle to the needle pathway. The needle angle is determined by measuring the acute angle between line $\mathrm{A}$ and line $\mathrm{B}$.

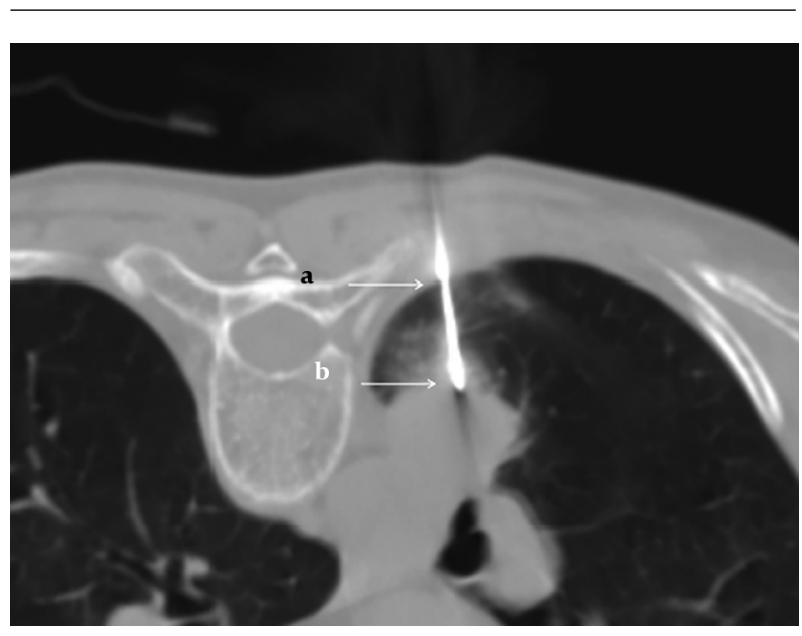

Figure 3. The depth from the pleural surface was measured from the point of pleural puncture (a) to the nearest edge of the lung lesion (b) along the needle pathway. 
was considered statistically significant for multiple comparisons. Other confounding factors such as gender, age, lesion size, and location were compared between procedural success and procedural failure groups by using MannWhitney U test or chi-square tests.

Comparison of procedural success rate and complication rate for each period was performed using a trend test. A P value less than 0.05 was considered statistically significant.

\section{Results}

The study included 435 men (65.7\%) and 227 women (34.3\%), with a mean age of 65.69 years (range: $25-89$ years). Mean lesion size was $4.0 \mathrm{~cm}$ (range: $0.5-13.6 \mathrm{~cm}$ ). Mean lesion depth from the pleural surface was $1.94 \mathrm{~cm}$ (range: 0 $8.5 \mathrm{~cm}$ ).

Of the 689 cases of PCNB, 642 were categorized as procedural success (93.1\%), and the remaining 47 were categorized as procedural failure (6.9\%). The causes of procedural failure were inadequate tissue $(\mathrm{n}=39)$ or nonspecific findings $(\mathrm{n}=8)$ on histopathologic analysis. In the 39 cases of inadequate tissue, pathologic findings were as follows: atypical cells $(n=15)$; normal biopsy tract elements including skin, muscle and lung parenchyma $(\mathrm{n}=18)$, and scant cellularity $(n=6)$. Chronic inflammation was considered to be a nonspecific finding. Among 48 cases exhibiting chronic inflammation, 40 showed no change in lesion size, or a reduction in size, and were therefore categorized as procedural success. Meanwhile, eight cases showed hot uptake on positron emission tomography (PET)-CT, or were confirmed to be a malignancy on surgical biopsy or repeated PCNB; they were categorized as procedural failure (Table 1). Of the rest of 40 cases, $67.5 \%$ (27/40) showed decrease in size, $27.5 \%(11 / 40)$ remained stable on follow up and 5\% (2/40) turned out to be benign on surgical resection. Therefore, they were categorized as procedural success. Both of two cases with surgical biopsy were confirmed to be organizing pneumonia. Details of the biopsy results of procedural success group are listed in Figure 1.

There was no significant correlation between needle angle and procedural success $(\mathrm{P}=0.568)$ (Table 2). Furthermore, there was no significant difference in lesion depth between cases categorized as procedural success and those categorized as procedural failure $(\mathrm{P}=0.144)$ (Table 2). However, the mean lesion depth tended to be greater among cases categorized as procedural failure compared to those categorized as procedural success. The mean lesion depths and standard deviations for cases categorized as procedural success and those categorized as procedural failure are provided in Table 2.

Procedural success group had a significantly larger lesion size compared to the procedural failure group (3.5 vs

\begin{tabular}{ll}
\hline Table 1. Pathologic Results of Procedural Failure & \\
\hline & Pathologic results $(\mathbf{N}=\mathbf{4 7}$ ) \\
\hline Inadequate tissue $(\mathbf{N}=\mathbf{3 9})$ & 15 \\
\hline \multicolumn{1}{|c}{ Atypical cells } & 18 \\
\hline \multicolumn{1}{c}{ Skin, muscle or lung parenchyma } & 6 \\
\hline \multicolumn{1}{c}{ Scant cellularity } & \\
\hline $\begin{array}{l}\text { Nonspecific finding such as chronic } \\
\text { inflammation }(\mathbf{N}=\mathbf{8})\end{array}$ & 2 \\
\hline $\begin{array}{l}\text { Hot uptake on PET-CT } \\
\text { Malignancy on surgical biopsy or repeated } \\
\text { PCNB }\end{array}$ & 6 \\
\hline
\end{tabular}

Abbreviation: PCNB, percutaneous core needle biopsy; PET, positron emission tomography.

\begin{tabular}{|c|c|c|c|}
\hline & $\begin{array}{c}\text { Procedural } \\
\text { success }\end{array}$ & $\begin{array}{c}\text { Procedural } \\
\text { failure }\end{array}$ & P value \\
\hline Total & $642(93.1)$ & $47(6.9)$ & \\
\hline Sex & & & $0.356^{\mathrm{b}}$ \\
\hline Male & $425(93.8)$ & $28(6.2)$ & \\
\hline Female & $217(91.9)$ & $19(8.1)$ & \\
\hline Age, $y$ & & & $0.46^{\mathrm{c}}$ \\
\hline Median & 69 & 68 & \\
\hline Range & $25-89$ & $32-84$ & \\
\hline Lesion size, $\mathrm{cm}$ & & & $0.007^{c}$ \\
\hline Median & 3.5 & 2.6 & \\
\hline Range & $0.5-13.6$ & $0.9-12$ & \\
\hline Lesion location & & & $0.408^{\mathrm{b}}$ \\
\hline RUL & $213(91.8)$ & $19(8.2)$ & \\
\hline RML & $41(89.1)$ & $5(10.9)$ & \\
\hline RLL & $109(95.6)$ & $5(4.4)$ & \\
\hline LUL & $170(95)$ & $9(5)$ & \\
\hline LLL & $107(92.2)$ & $9(7.8)$ & \\
\hline Needle angle, ${ }^{\circ}$ & & & $0.568^{\mathrm{d}}$ \\
\hline $0-30$ & $552(92.8)$ & $43(7.2)$ & \\
\hline $31-60$ & $74(97.4)$ & $2(2.6)$ & \\
\hline $61-90$ & $16(88.9)$ & $2(11.1)$ & \\
\hline Lesion depth, cm & $1.91 \pm 1.85$ & $2.38 \pm 2.10$ & $0.144^{\mathrm{c}}$ \\
\hline
\end{tabular}

Abbreviations: LLL, left lower lobe; LUL, left upper lobe; RLL, right lower lobe; RML, right middle lobe; RUL, right upper lobe; SD, standard deviation.

${ }^{a}$ Values are expressed as No. (\%) or mean \pm SD.

${ }^{\mathrm{b}}$ Chi-square test.

${ }^{\mathrm{C}}$ Mann-Whitney U test.

${ }^{\mathrm{d}}$ Trend test.

$2.6 \mathrm{~cm}, \mathrm{P}=0.007$ ). There were no statistically significant differences between procedural success and failure groups 
in another clinical data including age, sex, and lesion characteristics including location (Table 2 ).

Complications occurred in 123 of 689 cases (17.9\%), including pneumothorax, hemothorax, hemoptysis, pneumomediastinum, dyspnea, and soft tissue hemorrhage. Among these 123 cases, 15 were categorized as major complications (2.2\%), based on severity or requirement for an additional procedure. Detailed data regarding complications are shown in Table 3. The relationships between complications and needle angle, as well as between complications and lesion depth, are shown in Table 4. No significant correlation was found between complications and needle angle $(\mathrm{P}=0.101)$. However, Kruskal-Wallis test showed that there was a statistically significant difference in lesion depth between complication groups $(\mathrm{P}<0.001)$. On Bonferroni post hoc analysis, the lesion depth of the no complication group was significantly smaller than both minor and major complication groups $(\mathrm{P}<0.01)$. Moreover, the lesion depth of the minor complication group was also smaller compared to the major complication group $(\mathrm{P}=$ 0.002). Box plots of Figure 4 shows that the lesion depth was greater in cases involving complications, and tended to increase with severity.

\begin{tabular}{lc}
\hline Table 3. Complications of PCNB $(\mathrm{N}=123)^{\mathrm{a}}$ & \multicolumn{1}{c}{ Values } \\
\hline Complications & $96 / 123(13.9)$ \\
\hline Pneumothorax & $81 / 123(11.8)$ \\
\hline \multicolumn{1}{c}{ Small pneumothorax (last $<48$ hours) } & $15 / 123(2.2)$ \\
$\quad$ Large pneumothorax $($ last $>48$ hours $)$ or chest tube $^{\text {insertion }}{ }^{\text {bemothorax }}$ & $12 / 123(1.7)$ \\
\hline Hemoptysis & $12 / 123(1.7)$ \\
\hline Pneumomediastinum & $1 / 123(0.1)$ \\
\hline Dyspnea & $1 / 123(0.1)$ \\
\hline Soft tissue hemorrhage & $1 / 123(0.1)$ \\
\hline
\end{tabular}

Abbreviations: PCNB, percutaneous core needle biopsy.

${ }^{a}$ Values are expressed as No. (\%).

${ }^{\mathrm{b}}$ Pneumothorax was the only observed major complication.

When comparing complication rates and success rates in three equal periods, there was no significant difference between the three groups in both complication and success rates (Table 5).

\section{Discussion}

In the present study, we investigated factors influencing the procedural success and complications of PCNB of intrapulmonary lesions, with a particular focus on needle angle and lesion depth. The overall success rate of PCNB was $93.1 \%$, which is consistent with the findings reported by Zhao et al. (5) Lee et al. (8), and Hwang al. (9). As in the study by Zhao et al. (5), our study showed that neither needle angle nor lesion depth significantly influenced procedural success. Conversely, Ohno et al. (6) found that diagnostic accuracy for needle lengths of $\leq 40 \mathrm{~mm}$ was significantly greater than that for needle lengths $>40 \mathrm{~mm}(\mathrm{P}<$ $0.05)$. This may accord with our study, in that our cases categorized as procedural success had a shorter mean lesion depth than those categorized as procedural failure, even if the difference was not statistically significant. The mean lesion depth of both procedural success and procedural failure group was smaller than threshold suggested by Ohno et al. (6) and this could be the reason for statistical insignificance.

According to most previous studies, lesion size is a relatively well-known factor affecting procedural success (5, 10). In our study as well, among another associated factors, only lesion size showed significant difference. The procedural success group tended to have a larger lesion size compared to the procedural failure group.

Pneumothorax is the most common complication of PCNB. In our study, the incidence of pneumothorax was $13.9 \%$, and that of chest tube placement or large pneumothorax that lasted more than 48 hours was $2.2 \%$. These incidence rates were within the range reported in prior literature (11-15). Other complications were less frequent (e.g., hemothorax or hemoptysis, $1.7 \%$ ). Among various complications, only pneumothorax led to major complications.

Our study showed that lesion depth was significantly associated with both the occurrence and severity of complications. These results were consistent with those of previous reports $(2,6,16)$. Ohno et al. (6) suggested that a longer needle pathway might increase the chance of tearing the pleura and normal lung tissue, as the patient breathes during the PCNB procedure. We speculated that for deeper lesions, there is a greater chance of crossing additional tissue planes and pulmonary vessels, which may result in further complications.

Unlike lesion depth, needle angle did not influence the rate of complications in the present study. In contrast, Saji et al. (2) reported that needle angle constituted a novel predictor of complications, and suggested that needle angle may be significantly correlated with the requirement for chest tube placement as treatment for pneumothorax. There are some reasons for this contradictory result. First of all, the method of measuring the needle angle was different from our study. We did not choose the angle between a line perpendicular to the pleural surface and the needle tract because we thought that this might have a limit to the variety of angles. In addition, since a line perpendicular to the CT table is used as the reference for the needle angle at the time of CT-guided PCNB procedure in actual clinical practice, this method was chosen to reflect the ac- 


\begin{tabular}{|c|c|c|c|c|}
\hline & No complications & Minor complications & Major complications & Pvalue \\
\hline Needle angle, ${ }^{\circ}$ & & & & $0.101^{\mathrm{b}}$ \\
\hline $0-30$ & $483(81.2)$ & $98(16.5)$ & $14(2.4)$ & \\
\hline $31-60$ & $67(88.2)$ & $8(10.5)$ & $1(1.3)$ & \\
\hline Lesion depth, cm & $1.49 \pm 1.65$ & $3.39 \pm 1.71$ & $4.72 \pm 1.54$ & $<0.01^{\mathrm{c}}$ \\
\hline \multicolumn{5}{|l|}{ Comparison } \\
\hline No complications vs. minor complications & & & & $<0.01^{\mathrm{d}}$ \\
\hline No complications vs. major complications & & & & $<0.01^{d}$ \\
\hline Minor complications vs. major complications & & & & $0.002^{\mathrm{d}}$ \\
\hline
\end{tabular}

${ }^{\mathrm{a}}$ Values are expressed as No. (\%) or mean \pm SD.

${ }^{\mathrm{b}}$ Trend test.

${ }^{\mathrm{c}}$ Kruskal-Wallis test.

${ }^{d} \mathrm{P}<0.0167$ was considered statistically significant with Bonferroni correction. Comparsions of lesion depth depending on complications severity were performed.

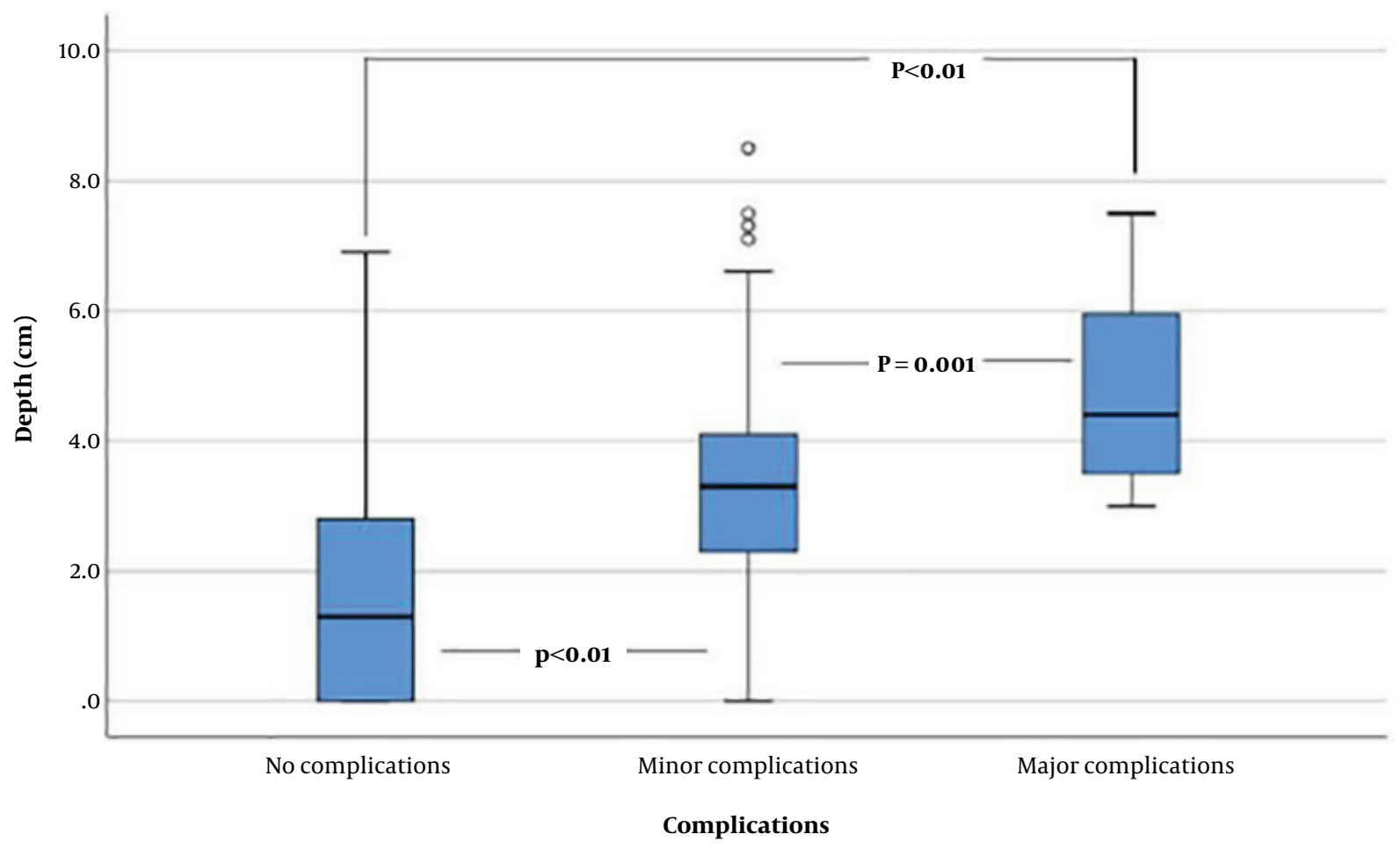

Figure 4. Box and whisker plots for lesion depth by complications

tual clinical setting. Second, Saji et al. (2) speculated that a greater angle has less chance to get a satisfactory biopsy result and concluded that the angulation might have correlation to the number of needle pass. However, unlike Saji et al. (2), more than one needle pass during a single biopsy attempt was excluded from our study and there is no possibility that the angle would be affected by the num- ber of needle passes. In addition, to the best of our knowledge, there have been no major studies of relatively large populations, such as that in the present study. Moreover, in most prior reports (including that of Saji et al. (2), PCNBs were performed by several radiologists. Notably, this might impact the outcomes of PCNB (2,17-20). Indeed, Otto et al. (4) reported differences in the rates of complications 


\begin{tabular}{|c|c|c|c|c|}
\hline & Group 1 & Group 2 & Group 3 & Pvalue \\
\hline Complications & & & & $0.12 \mathrm{a}$ \\
\hline No complications & $169(83.3)$ & $233(89.6)$ & $164(72.6)$ & \\
\hline Minor complications & $28(13.8)$ & $24(9.2)$ & $54(24.8)$ & \\
\hline Procedural success & & & & $0.934 a$ \\
\hline Procedural success & $187(92.1)$ & $247(95)$ & $208(92)$ & \\
\hline Procedural failure & $16(7.9)$ & $13(5)$ & $18(8)$ & \\
\hline
\end{tabular}

${ }^{a}$ Values are expressed as No. (\%).

${ }^{b}$ Group 1, from July 2004 to September 2008; group 2, from October 2008 to December 2012; group 3, from January 2013 to March 2017.

${ }^{\mathrm{c}}$ Trend test.

of PCNB among radiologists. Therefore, our study differs in that PCNB was performed on a relatively large number of patients without the variation seen when the procedure was performed by multiple radiologists. Furthermore, few wide-angle cases in our study could bias results, which may lead to differences relative to previous reports.

As mentioned above, Otto et al. (4) found a significant difference of the outcomes of PCNB between different radiologists. Therefore, to control this confounding factor, we conducted a study with cases performed by a single radiologist. Moreover, we also found that in the same radiologist, there was no significant association between PCNB outcomes (including success rate and complications) and his/her experience based on years of clinical activity.

There may have been limitations to our study. First, we did not exclude emphysema, which has been reported in many studies $(6,21-23)$ as a potential confounding factor that may affect accuracy and complication rates. Thus, there is a possibility that the measured rate of pneumothorax was higher than the actual rate. Second, this study used a single-center design with one radiologist, and most PCNB procedures were performed at a shallow angle in our institution. Thus, nearly $70 \%$ of the cases in our study were in the $0^{\circ}-30^{\circ}$ group, and a relatively small number of wideangle cases were included; this may have constituted a selection bias. Third, because the angle was measured manually, rather than automatically (i.e., via machine), the data may have been subjective and thus prone to error.

In conclusion, in CT-guided PCNB, needle angle had no effect on both procedural success and complications. Also, there was no significant correlation between lesion depth and procedural success. However, lesion depth was closely correlated with the incidence and severity of complications after PCNB.

\section{Footnotes}

Authors' Contributions: Study concept and design: In Jae Lee and Jee Hyeon Lee. Acquisition of data: In Jae Lee. Analysis and interpretation of data: In Jae Lee and Jee Hyeon Lee. Drafting of the manuscript: In Jae Lee and Jee Hyeon Lee. Critical revision of the manuscript for important intellectual content: In Jae Lee. Statistical analysis: In Jae Lee and Jee Hyeon Lee.

Conflict of Interests: The author(s) declared no potential conflicts of interest with respect to the research, authorship, and/or publication of this article.

Ethical Approval: The ethical approval number was 2019-06-016-001 (https://www.eirb.com:3443/common/nirbindex.jsp 2019-06-016-001).

Funding/Support: The author(s) received no financial support for the research, authorship, and/or publication of this article.

\section{References}

1. Geraghty PR, Kee ST, McFarlane G, Razavi MK, Sze DY, Dake MD. CTguided transthoracic needle aspiration biopsy of pulmonary nodules: Needle size and pneumothorax rate. Radiology.2003;229(2):47581. doi: 10.1148/radiol.2291020499. [PubMed: 14595149].

2. Saji H, Nakamura H, Tsuchida T, Tsuboi M, Kawate N, Konaka C, et al. The incidence and the risk of pneumothorax and chest tube placement after percutaneous CT-guided lung biopsy: The angle of the needle trajectory is a novel predictor. Chest. 2002;121(5):1521-6. doi: 10.1378/chest.121.5.1521. [PubMed: 12006438].

3. Lee HY, Lee IJ. Assessment of independent risk factors of developing pneumothorax during percutaneous core needle lung biopsy: Focus on lesion depth. Iran J Radiol. 2016;13(4). e30929. doi: 10.5812/iranjradiol.30929. [PubMed: 27895865]. [PubMed Central: PMC5116566].

4. Otto S, Mensel B, Friedrich N, Schafer S, Mahlke C, von Bernstorff $\mathrm{W}$, et al. Predictors of technical success and rate of complications of image-guided percutaneous transthoracic lung needle biopsy of pulmonary tumors. PLoS One. 2015;10(4). e0124947. doi: 10.1371/journal.pone.0124947. [PubMed: 25855983]. [PubMed Central: PMC4391827]. 
5. Zhao G, Shi X, Sun W, Liang H, Mao X, Wen F, et al. Factors affecting the accuracy and safety of computed tomography-guided biopsy of intrapulmonary solitary nodules $<\mid=30 \mathrm{~mm}$ in a retrospective study of 155 patients. Exp Ther Med. 2017;13(5):1986-92. doi: 10.3892/etm.2017.4179. [PubMed: 28565797]. [PubMed Central: PMC5443260].

6. Ohno Y, Hatabu H, Takenaka D, Higashino T, Watanabe H, Ohbayashi C, et al. CT-guided transthoracic needle aspiration biopsy of small (< or $=20 \mathrm{~mm}$ ) solitary pulmonary nodules. AJR Am J Roentgenol. 2003;180(6):1665-9. doi: 10.2214/ajr.180.6.1801665. [PubMed: 12760939].

7. Filippiadis DK, Binkert C, Pellerin O, Hoffmann RT, Krajina A, Pereira PL. Cirse quality assurance document and standards for classification of complications: The cirse classification system. Cardiovasc Intervent Radiol. 2017;40(8):1141-6. doi: 10.1007/s00270-017-1703-4. [PubMed: 28584945].

8. Lee IJ, Bae YA, Kim DG, Jung KS, Im HJ, Lee K, et al. Percutaneous needle aspiration biopsy (PCNAB) of lung lesions: 5 years results with focusing on repeat PCNAB. Eur J Radiol. 2010;73(3):551-4. doi: 10.1016/j.ejrad.2009.01.009. [PubMed:19200679].

9. Hwang HS, Chung MJ, Lee JW, Shin SW, Lee KS. C-arm cone-beam CT-guided percutaneous transthoracic lung biopsy: Usefulness in evaluation of small pulmonary nodules. AJR Am J Roentgenol. 2010;195(6):W400-7. doi: 10.2214/AJR.09.3963. [PubMed: 21098171].

10. Tongbai T, McDermott S, Kiranantawat N, Muse VV, Wu CCC, Shepard JAO, et al. Non-diagnostic CT-guided percutaneous needle biopsy of the lung: Predictive factors and final diagnoses. Korean J Radiol. 2019;20(11):1515-26. doi: 10.3348/kjr.2019.0014. [PubMed: 31606956]. [PubMed Central: PMC6791813].

11. Klein JS, Salomon G, Stewart EA. Transthoracic needle biopsy with a coaxially placed 20-gauge automated cutting needle: Results in 122 patients. Radiology. 1996;198(3):715-20. doi: 10.1148/radiology.198.3.8628859. [PubMed: 8628859].

12. Collings CL, Westcott JL, Banson NL, Lange RC. Pneumothorax and dependent versus nondependent patient position after needle biopsy of the lung. Radiology. 1999;210(1):59-64. doi: 10.1148/radiology.210.1.r99ja1759. [PubMed: 9885587].

13. Wu CC, Maher MM, Shepard JA. Complications of CT-guided percutaneous needle biopsy of the chest: Prevention and management. AJR Am J Roentgenol. 2011;196(6):W678-82. doi: 10.2214/AJR.10.4659. [PubMed: 21606253].

14. Wiener RS, Schwartz LM, Woloshin S, Welch HG. Population-based risk for complications after transthoracic needle lung biopsy of a pulmonary nodule: An analysis of discharge records. Ann Intern Med. 2011;155(3):137-44. doi: 10.7326/0003-4819-155-3-201108020 00003. [PubMed: 21810706]. [PubMed Central: PMC3150964].

15. Winn N, Spratt J, Wright E, Cox J. Patient reported experiences of CT guided lung biopsy: A prospective cohort study. Multidiscip Respir Med. 2014;9(1):53. doi: 10.1186/2049-6958-9-53. [PubMed: 25379180]. [PubMed Central: PMC4221673].

16. Hiraki T, Mimura $\mathrm{H}$, Gobara $\mathrm{H}$, Shibamoto $\mathrm{K}$, Inoue D, Matsui $\mathrm{Y}$, et al. Incidence of and risk factors for pneumothorax and chest tube placement after CT fluoroscopy-guided percutaneous lung biopsy: Retrospective analysis of the procedures conducted over a 9-year period. AJR Am J Roentgenol. 2010;194(3):809-14. doi: 10.2214/AJR.09.3224. [PubMed: 20173164].

17. Tsukada H, Satou T, Iwashima A, Souma T. Diagnostic accuracy of CTguided automated needle biopsy of lung nodules. AJR Am J Roentgenol. 2000;175(1):239-43. doi:10.2214/ajr.175.1.1750239. [PubMed: 10882279].

18. Li H, Boiselle PM, Shepard JO, Trotman-Dickenson B, McLoud TC. Diagnostic accuracy and safety of CT-guided percutaneous needle aspiration biopsy of the lung: Comparison of small and large pulmonary nodules. AJR Am J Roentgenol. 1996;167(1):105-9. doi: 10.2214/ajr.167.1.8659351. [PubMed: 8659351].

19. Kazerooni EA, Lim FT, Mikhail A, Martinez FJ. Risk of pneumothorax in CT-guided transthoracic needle aspiration biopsy of the lung. Radiology. 1996;198(2):371-5. doi: 10.1148/radiology.198.2.8596834. [PubMed: 8596834].

20. Cox JE, Chiles C, McManus CM, Aquino SL, Choplin RH. Transthoracic needle aspiration biopsy: Variables that affect risk of pneumothorax. Radiology.1999;212(1):165-8. doi:10.1148/radiology.212.1.r99jl33165. [PubMed: 10405737].

21. Li Y, Du Y, Yang HF, Yu JH, Xu XX. CT-guided percutaneous core needle biopsy for small $(<=20 \mathrm{~mm})$ pulmonary lesions. Clin Radiol. 2013;68(1):e43-8. doi: 10.1016/j.crad.2012.09.008. [PubMed: 23177650].

22. Choi JW, Park CM, Goo JM, Park YK, Sung W, Lee HJ, et al. C-arm cone-beam CT-guided percutaneous transthoracic needle biopsy of small $(</=20 \mathrm{~mm})$ lung nodules: diagnostic accuracy and complications in 161 patients. AJR Am J Roentgenol. 2012;199(3):W322-30. doi: 10.2214/AJR.11.7576. [PubMed: 22915422].

23. Heerink WJ, de Bock GH, de Jonge GJ, Groen HJ, Vliegenthart R, Oudkerk M. Complication rates of CT-guided transthoracic lung biopsy: Meta-analysis. Eur Radiol. 2017;27(1):138-48. doi: 10.1007/s00330-0164357-8. [PubMed: 27108299]. [PubMed Central: PMC5127875]. 